\title{
A crise mundial de 2008 e o golpe do capital na política de saúde no Brasil
}

\author{
The global crisis of 2008 and the coup of capital in Brazilian health \\ policy
}

Carmen Fontes de Souza Teixeira', Jairnilson Silva Paim²

DOI: 10.1590/0103-11042018S201

1 Universidade Federal da Bahia (UFBA), Instituto de Humanidades, Artes e Ciências Professor Milton Santos (IHAC) - Salvador (BA), Brasil. Orcid: https://orcid. org/0000-0002-80809146

carment@ufba.br

2 Universidade Federal da Bahia (UFBA), Instituto de Saúde Coletiva (ISC) Salvador (BA), Brasil. Orcid: https://orcid. org/0000-0003-0783$262 X$

jairnil@ufba.br
RESUMO O objetivo do artigo foi analisar a conjuntura posterior às eleições presidenciais de 2014, discutindo possíveis relações com a crise econômica mundial e com os desdobramentos do golpe de 2016 na saúde. Trata-se de um artigo de opinião que contemplou a análise dos principais fatos políticos do período. Os resultados ressaltam que a financeirização da saúde, o ajuste fiscal, a restauração do neoliberalismo e o clientelismo político da direita têm gerado o desmonte do Sistema Único de Saúde (SUS), vis-à-vis alguma resistência de frentes e movimentos sociais progressistas. Conclui-se pela necessidade de acúmulo de energias políticas para alterar a correlação de forças na atual conjuntura.

PALAVRAS-CHAVE Política de saúde. Sistema Único de Saúde. Reforma dos serviços de saúde.

ABSTRACT The objective of the article is to analyze the conjuncture after the 2014 presidential elections, by discussing possible connections with the global economic crisis and the unfolding of the 2016's coup d'etat in the health context. It is an opinion article that contemplated the analysis of the main political facts of the period above mentioned. The results highlight that the financialization of health, the fiscal adjustment, the restoration of neoliberalism, and the political clientelism of the right-wing political party have caused the breakdown of the SUS (Unified Health System), facing some resistance of fronts and progressive social movements. It is concluded the need for accumulation of political energies to change the correlation of forces in the current conjuncture.

KEYWORDS Health policy. Unified Health System. Health care reform. 


\section{Introdução}

A crise mundial de 2008 tem sido reconhecida como manifestação de contradições do capitalismo na qual se destacam a queda tendencial da taxa de lucro, os problemas gerados pelo subprime (modalidade de empréstimos como crédito de risco) e a especulação imobiliária nos Estados Unidos e em países europeus. A resposta dos países dominantes a essa crise foi a estatização das dívidas para salvar os bancos e seus executivos, assim como a ênfase em políticas neoliberais e o reforço na financeirização da economia, ampliando as críticas e os combates contra as políticas universais e o Welfare State.

Aproveitando essa oportunidade, o capital realizou uma ofensiva contra a saúde'. Sistemas nacionais de saúde sofreram comprometimento da universalidade, aprofundando políticas de competição regulada e comercialização ${ }^{2}$, bem como fortalecendo as tendências de segmentação e de mercantilização na saúde. Assim, interesses de mercado impuseram políticas de austeridade fiscal neoliberais na Europa pela troika (Fundo Monetário Internacional - FMI, Banco Central Europeu e Comissão Europeia), com impacto negativo nas instituições de saúde estruturadas no século $X^{3}$. Houve cortes com restrições de serviços, ampliação de copagamentos, transferência de custos para os usuários, diminuição de responsabilidades por parte do Estado e aumento nas formas de privatização. Na América Latina, a privatização observada nos sistemas de saúde do Chile, da Colômbia, do México e da Argentina não se mostrou efetiva, aumentando a barreira de acesso e custos administrativos, enquanto no caso colombiano apontava para a insolvência'.

Tal ofensiva em outros países não deve escamotear determinantes histórico-estruturais internos que conformaram uma sociedade extremamente desigual como a brasileira, nem obscurecer a crise do Sistema Único de Saúde (SUS), observada desde a aprovação da Constituição Federal de 1988, e expressa no subfinanciamento, na articulação público-privada, na gestão e na desvalorização dos trabalhadores de saúde. Desse modo, várias perguntas emergem na conjuntura recente: quais os desdobramentos da crise de 2008 no Brasil? Até que ponto essa crise pôde ser adiada mediante políticas anticíclicas dos governos Lula e Dilma? Será que se expressou em crises econômica, ética e política desde 2014? Quais as repercussões nas políticas sociais e no SUS, especialmente depois do golpe de 2016?

Nessa perspectiva, o objetivo do presente estudo é analisar a conjuntura posterior às eleições presidenciais de 2014, discutindo possíveis relações com a crise econômica mundial e com certos desdobramentos do golpe de 2016 na política de saúde.

\section{Alguns antecedentes}

De Sarney a Dilma, o orçamento da seguridade social não foi adotado, e suas fontes de recursos foram segmentadas e desviadas para financiar a economia. Parte do financiamento da seguridade social foi capturada pela área econômica dos diferentes governos, e a questão social passou a ser conduzida por meio de programas emergenciais e políticas focalizadas, defendidas por especialistas e preconizadas por instituições internacionais como o Banco Mundial (BM). Cabe reconhecer, entretanto, que os programas de transferência condicionada de renda ${ }^{4}$, a exemplo do 'Bolsa Família', apresentaram efeitos positivos na redução da pobreza e da desigualdade social, com consequente geração de dividendos políticos-ideológicos.

Nem a sociedade nem o Estado brasileiro têm apostado no projeto da Reforma Sanitária Brasileira (RSB) e optado pelo SUS como política prioritária, sendo boicotado sucessivamente por vários governos desde a Constituição de $1988^{4}$. Grandes desafios continuavam postos para a RSB e para a consolidação do SUS, 
enquanto sistema de saúde público, universal, igualitário, integral e de qualidade.

Costa, Bahia e Scheffer ${ }^{5}$, ao analisarem posições ambíguas do governo Dilma em relação à articulação público-privada, denunciaram desde então ameaças contra o SUS decorrentes de pressões dos que apostavam na privatização, tanto nos setores à direita quanto à esquerda do espectro político. Alertaram que mais subsídios e desonerações fiscais para a expansão do mercado de assistência médica suplementar deparavam-se com um acúmulo de experiências negativas de consumidores iludidos de que o mercado seria capaz de atender às suas necessidades. Desde aquela época, não se vislumbrava um cenário otimista para a sustentabilidade do SUS. Mesmo se conseguindo mais recursos, outras lutas seriam necessárias para evitar a adoção do modelo americano e para não permanecer refém da indústria de equipamentos e de medicamentos, dos hospitais privados e do corporativismo de profissionais.

Assim, a crise do SUS antecedeu a crise mundial e as crises econômica, política e ética constatadas no Brasil a partir de 2014. Aliás, as forças sociais e políticas que formularam a RSB e o SUS já acumulavam derrotas desde o período pós-constituinte ${ }^{4}$. Entretanto, nas primeiras duas décadas desse período, as medidas contra o SUS limitavam-se ao Executivo; até quando o Congresso extinguiu a Contribuição Provisória sobre Movimentação Financeira (CPMF) em 2007. Já na década seguinte, o Executivo e o Legislativo rejeitaram a proposta de $10 \%$ das receitas brutas da União para a saúde, ignorando o movimento Saúde+10. Juntos comprometeram a sustentabilidade econômica do SUS e permitiram a abertura da saúde ao capital estrangeiro. Em 2014, chegou a vez do Judiciário, reconhecendo a constitucionalidade das Organizações Sociais (OS) no Supremo Tribunal Federal (STF) depois de 17 anos de protelação e configurando uma porta aberta para as parcerias público-privadas (PPP), terceirizações, OS, Organização da Sociedade Civil de Interesse Público (Oscip) ${ }^{6}$ etc.

\section{O 'ensaio desenvolvimentista', a polarização das eleições e o golpe do capital}

Nos anos de 2011 e 2012, os desenvolvimentistas do governo Dilma atuaram sobre o mercado financeiro, ampliando espaços para bancos públicos e reduzindo os juros, mas o Banco Central voltou a elevar a taxa Selic em abril de 2013. Assim, o governo devolveu ao mercado o controle sobre a política econômica, comprometendo a retomada do desenvolvimento e o avanço progressista. Nessa conjuntura, o capital financeiro, aparentemente diferenciado do capital industrial e da fração organizada dos trabalhadores que formavam a coalizão produtivista, aliou-se à classe média tradicional, reforçando a coalizão rentista. Enquanto isso, o subproletariado permanecia sob as asas do lulismo, que arbitrava as forças sociopolíticas ${ }^{7}$.

Entre o maio do ensaio desenvolvimentista - quando a presidente Dilma fez uma forte crítica aos juros praticados pelos bancos no País e anunciou, no Dia dos Trabalhadores de 2012, a redução nas taxas de juros - e as Jornadas de Junho de 2013, algo precisa ser entendido e explicado. Nesse interregno, os comentaristas econômicos, economistas, representantes do mercado financeiro e a grande mídia anunciavam a possível volta da inflação. Ademais, o governo federal combinou com os estados e municípios para adiarem o reajuste das tarifas de transportes coletivos até junho de 2013 para que os aumentos não incidissem sobre as taxas de inflação. Esse fato pode ser um dos elementos que faltavam para entender o nexo entre a crise mundial de 2008, a política econômica 
de Dilma/Guido Mantega e as manifestações de junho de 2013, incluindo posteriormente o golpe do capital.

Os limites do neodesenvolvimentismo geraram espaço para a política, aproveitado pelos conservadores e pela direita desde as Jornadas de Junho de 2013. O capital industrial afastou-se de Dilma, alinhando-se ao bloco rentista de oposição, devido aos seguintes motivos: 1) Mistura do capital da indústria e das finanças; 2) Pleno emprego, força dos sindicatos e elevação dos salários reais; 3) Ideologia anti-intervencionista; 4) Correlação de forças internacional; 5) Abertura de excessivas frentes de luta 7 .

Do lado do governo, foi elaborada a chamada Nova Matriz econômica (NME), integrando as seguintes medidas: redução dos juros; uso intensivo do Banco Nacional de Desenvolvimento Econômico e Social (BNDES); aposta na reindustrizalização; desonerações; plano para infraestrutura; reforma do setor elétrico; desvalorização do real para facilitar as exportações; controle de capitais; e proteção ao produto nacional. Contudo o agravamento da crise internacional, desde 2011, ao lado de uma possível redução das taxas de lucro, levou os principais grupos empresariais brasileiros, liderados pelos bancos privados, a demandar do governo federal políticas de austeridade no sentido contrário ao ensaio desenvolvimentista, visando

aprofundar o ajuste recessivo, aumentar o desemprego e conter o ciclo grevista, a fim de impor uma série de reformas antipopulares, como a da previdência e a trabalhista8(59-60).

O cerco a favor da reversão neoliberal contou com apoio da burguesia, classe média, setores da classe trabalhadora, além de personalidades influentes sobre Dilma. Com as eleições de 2014, o choque recessivo e a opção de acelerar o lulismo terminaram por produzir a pior recessão desde 19927. A partir de então, aumentou a oposição do capital e dos seus representantes ao governo Dilma, aprofundando a polarização nas eleições de 2014.
Paradoxalmente, após a vitória apertada do segundo turno, a presidente adotou a política econômica defendida pelo seu oponente durante a campanha. Essa opção, obviamente, ia no sentido contrário das expectativas dos seus eleitores, fragilizando a sua base social e a sua sustentação política. O capital financeiro inicialmente parecia preferir Dilma à instabilidade, mas não foi acompanhado por empresários industriais. Essas frações se articularam depois e deram o golpe de 2016, liderado pelo vice-presidente e por parte dos seus ministros, com a "ajuda do Congresso [...] e de uma mídia e uma Justiça partidarizada"9(49).

As políticas de austeridade implantadas pelos ministros Joaquim Levi e Nelson Barbosa, em 2015, foram radicalizadas pelo governo interino, a partir de 12 de maio de 2016, e expandidas com a consumação final do golpe de 31 de agosto. Com efeito, uma soma fabulosa do orçamento tem sido apropriada pelo capital financeiro. Em 2014, quase 1 trilhão de reais ( $\mathrm{R} \$ 978$ bilhões) do orçamento da União executado foi destinado ao pagamento da dívida pública (45,11\%). Para a saúde, coube apenas 3,98\%. Correspondiam às parcelas informadas pelo governo a título de 'juros' (R\$ 170 bi) e 'amortizações' (R\$ 808 bi), ou seja, 12 vezes do que foi destinado à educação, 11 vezes à saúde, mais que o dobro dos gastos com a Previdência Social. Entre 2010 e 2014, o governo gastou só em juros R 700 bilhões; e com o Bolsa Família, R\$ 103 bilhões ${ }^{10}$.

\section{Repercussões das crises e do golpe na saúde}

Vale recordar os vários golpes desferidos contra o SUS desde 2014: 1) Abertura da saúde ao capital estrangeiro; 2) Projeto de Lei (PL) para obrigatoriedade de planos privados de saúde para empregados, exceto os domésticos; 3) PL das Terceirizações; 4) Prorrogação da Desvinculação das 
Receitas da União (DRU), acrescida da Desvinculação das Receitas dos Estados (DRE) e da Desvinculação das Receitas dos Municípios (DRM); 5) Proposta de Emenda Constitucional (PEC 241) da Câmara dos Deputados e PEC 55 do Senado (Novo Regime Fiscal); 6) Planos populares; 7) Rejeição da Emenda Popular Saúde $+10 ; 8)$ Orçamento impositivo; 9) Reconhecimento da constitucionalidade das OS; 10) Proposta de Cobertura Universal em Saúde; 11) Agenda Brasil com cobrança de serviços no SUS; 12) Novos pacotes de ajuste; 13) Saúde, educação e ciência e tecnologia como moeda de troca político-partidária. Cumpre registrar que parte dessas iniciativas já foi efetivada $(1,3,4,5,7,8,9,13)$, enquanto outras ainda pairam como ameaças concretas $(2,6,10,11,12)$.

Para além do plano fenomênico, houve modificações nas relações entre o Estado e o capital que vão além do financiamento das políticas sociais e do SUS. Uma dessas regras foi a mencionada abertura da saúde ao capital estrangeiro, aprovada no Congresso nacional e não vetada pela Presidência da República, o que gerou questionamentos de entidades do movimento sanitário.

Não foi apenas o então presidente da Câmara de Deputados nem mesmo o Congresso Nacional que impuseram essas derrotas, mas, especialmente, as operadoras de planos de saúde que financiaram as campanhas das eleições de 2010 e 2014. Portanto, o determinante fundamental desses retrocessos está representado pelo capital financeiro que define, direta e indiretamente, as políticas públicas no Brasil e no mundo.

Essa financeirização não é só uma hipertrofia do capital financeiro, nem uma patologia do sistema capitalista, mas um novo padrão sistêmico de acumulação de riqueza do capitalismo contemporâneo"1. Esta vai mais além que a privatização da saúde na infraestrutura, produção e consumo de serviços e gestão do sistema. Essas modalidades de privatização já eram bem conhecidas, estudadas e denunciadas pelo movimento sanitário. Trata-se, agora, de uma articulação público-privada específica, via empresas, que realizam a intermediação da assistência, ou seja, instituições financeiras que administram planos de saúde e se inserem no jogo especulativo das bolsas de valores. Esse processo está acompanhado do financiamento de campanhas de parlamentares e dirigentes do executivo, da cooptação de ministros da Fazenda, do Planejamento, da Casa Civil e da Saúde, assim como da captura da Agência Nacional de Saúde Suplementar (ANS), isto é, da ocupação de cargos de direção da ANS por empresários de planos de saúde, expressão do circuito entre gestores e técnicos da burocracia estatal e empresas do setor saúde ('porta giratória') e da produção e reprodução da corrupçãon $0^{11,12}$.

\section{O 'austericídio' e a saúde}

O 'austericídio' produzido pela implementação das medidas preconizadas na Emenda Constitucional 95 (EC-95), que congela os gastos públicos na área social para os próximos 20 anos, deve produzir resultados nefastos na saúde. Com o aumento da população e duplicação do percentual de idosos, ao tempo em que os recursos para a saúde serão pré-fixados pela inflação, certamente será drasticamente reduzido o gasto per capita com saúde. Isto, em um cenário epidemiológico que demandará exatamente o contrário, ou seja, o aumento do valor per capita investido em saúde ante os problemas e necessidades da população, e diante da tendência ao aumento dos custos da assistência, por conta da incorporação de tecnologias de alta densidade de capital e de insumos adquiridos, em grande parte, em dólar.

Além disso, formou-se uma 'bomba-relógio' com a epidemia anunciada de diabetes e hipertensão de crianças e adultos jovens de hoje com obesidade e sobrepeso; com a epidemia atual de acidentes de motocicletas; com uma geração de crianças com Síndrome 
Neurológica da Zika; com pacientes sofrendo problemas articulares decorrentes da Chikungunya; com taxas elevadas de morbimortalidade por câncer; com prevalências elevadas de transtornos mentais, especialmente depressão; com o crescimento de violências e acidentes; com o envelhecimento da população; e com a tripla carga de doenças.

A proposta de planos de saúde acessíveis, por sua vez, expressa um movimento do capital na saúde que já vinha se conformando no País, corroendo a possibilidade de manutenção do SUS, enquanto um sistema público e universal de saúde. Essa proposta, mesmo que não entregue o que promete e iluda seus possíveis consumidores, é consistente com as políticas delineadas pelo governo e com os documentos divulgados pelos empresários da saúde desde as eleições de 2014.

Se os gastos federais cresceram mais que as receitas nos últimos anos, não foi por causa da saúde. Os recursos aplicáveis a ela estiveram estáveis em relação ao Produto Interno Bruto (PIB), aproximadamente 1,7\% deste. Representavam gastos que beneficiariam milhões de brasileiros, ao contrário de subsídios e desonerações.

\section{O curso e a agenda do retrocesso}

O governo Temer implementou, o mais rápido possível, a sua agenda de retrocesso por meio do corte das políticas sociais, recuo da legislação ambiental, retirada dos direitos trabalhistas e previdenciários, entrega do patrimônio público, tributação regressiva, restrição ao pensamento crítico e "na arbitrariedade escancarada da força policial”13(36).

Novas 'crises' da previdência têm sido fabricadas para justificar as reformas nos governos de Fernando Henrique Cardoso (FHC), Lula, Dilma e Temer, acionando o suposto deficit como pretexto. De acordo com os tecnoburocratas, os recursos da União deveriam reforçar o capitalismo, desonerando o capital e prevalecendo uma regra pétrea entre os economistas do poder segundo a qual o gasto social não deve pressionar o orçamento fiscal ${ }^{\mathbf{1 4}}$. Entretanto, quando ressurge a crise, esses recursos têm sido usados para socorrer a economia, seja comprando dólar nas crises cambiais, seja desonerando empresas e empresários, seja repassando bilhões do Tesouro Nacional para o BNDES viabilizar oferta de juros subsidiados.

Diante dessa conjuntura, as perspectivas para as políticas sociais se apresentavam bastante sombrias. No caso da saúde, está em curso um processo de americanização do sistema, tendo como cenário a expansão do mercado de serviços de saúde e subsídios, inclusive assimilando a proposta de 'cobertura universal em saúde’15.

\section{Novas bases sociais, forças políticas e estratégias?}

A guinada adotada pelo Partido dos Trabalhadores (PT) desde o final da década de $1980^{16}$ e, especialmente, a partir de 2003 o deslocou para o liberalismo social, vinculado ao pragmatismo político. Se este liberalismo social, sob o pretexto do realismo político, foi capaz de legitimar parcialmente o lulismo, possibilitando a vitória do PT nas eleições presidenciais de 2006, 2010 e 2014, de outro modo comprometeu as políticas universais, a exemplo do SUS, desconstruiu a seguridade social concebida pela Constituição Cidadã e deu prosseguimento ao seu desmonte iniciado pelos governos Collor e FHC.

Os projetos de reforma progressista, nacional, desenvolvimentista, democrático e redistributivo vinculados à Constituição Cidadã, como o 'Esperança e Mudança' e o 'Democrático-popular', foram derrotados por diferentes modos 4 . Até mesmo o neodesenvolvimentismo foi substituído por reformas conservadoras.

Além disso, os três poderes da República têm atuado na contramão da RSB e dos princípios e diretrizes do SUS. Constata-se uma ação do Estado contra o SUS, negligenciando 
o princípio constitucional segundo o qual a 'saúde é direito de todos e dever do Estado'. O movimento sanitário, mesmo mobilizando sujeitos sociais em defesa de um sistema de saúde universal, dispõe de bases de apoio insuficientes, pois não conquistou, efetivamente, trabalhadores, classe média e setores populares.

Diferentemente do que muitos imaginavam, a conjuntura que se foi desenhando desde as Jornadas de Junho de 2013 tem imposto um conjunto de derrotas ao SUS. A mobilidade na base da estrutura social verificada até 2014, com reforço do contingente de trabalhadores e um realinhamento político-eleitoral traduzido pelo lulismo, quando burgueses e proletários são substituídos por ricos e pobres no discurso político, não parece ter resultado em um avanço progressista.

Em 2015, dois grandes projetos disputaram ideologicamente a cena brasileira: a) Uma Ponte para o Futuro; b) O Brasil que queremos. O primeiro, formulado pela Fundação Ulisses Guimarães do então Partido do Movimento Democrático Brasileiro (PMDB), também conhecido como 'Plano Temer', contém uma agenda ultraliberal na perspectiva econômica e regressiva no que diz respeito aos direitos sociais. O segundo, articulado por pesquisadores, intelectuais e lideranças sindicais de São Paulo vinculados à Plataforma Social, foi debatido por diversas entidades do movimento da RSB, a exemplo do Centro Brasileiro de Estudos de Saúde (Cebes) e da Associação Brasileira de Saúde Coletiva (Abrasco). Este projeto, apoiado pelas forças progressistas, representava uma proposta alternativa ao projeto conservador, esboçando uma agenda de curto prazo centrada nas seguintes medidas: 1) Preservar o emprego e a renda; 2) Desarmar a armadilha recessiva; 3) Aprender com as lições da experiência internacional; 4) Baixar os juros; 5) Recompor a capacidade de financiamento do Estado; 6) Destravar os investimentos públicos e privados; 7) Fortalecer o mercado interno; 8) Preservar os gastos sociais. A proposta explicitava, ainda, as seguintes diretrizes; a) Defesa da Constituição de 1988; b) Preservar a inclusão social; c) Enfrentar as desigualdades e discriminações históricas; d) Enfrentar as desigualdades da renda e do patrimônio; e) Enfrentar as desigualdades na oferta de serviços e universalizar a cidadania. Além disso, propunha 'uma ampla mobilização social com o objetivo claro de lutar contra o atual modelo econômico', traduzido na política de ajuste fiscal na qual os povos pagam a conta e as classes dominantes se acertam em torno de uma agenda de desconstrução dos direitos sociais, do meio ambiente e de culturas ${ }^{17(49)}$.

A conjuntura delineada depois do golpe de 2016 possibilitou a implantação de parte do primeiro projeto e expressa um cenário ainda mais regressivo, extremamente grave e preocupante diante das medidas contrárias aos direitos sociais anteriormente assegurados pela Constituição de 1988. Vão contra os interesses nacionais e contra a democracia, além de comprometerem a vida e a saúde da classe trabalhadora e da população mais pobre deste país.

A financeirização e a hegemonia do capital financeiro, o ajuste fiscal violento (EC-95), a restauração radical do neoliberalismo e o clientelismo político da direita conservadora estão possibilitando o desmonte do SUS, ainda que gerando algum grau de resistência mediante frentes de movimentos sociais progressistas, conquistas de aparelhos da sociedade civil e algumas incursões no parlamento.

Esse ajuste significa mais que uma ameaça ao SUS universal ou à garantia de recursos do Estado para saúde e educação. Trata-se de um atentado do Executivo e do Legislativo à democracia e contra gerações de brasileiros nos próximos 20 anos. Do cadinho desses economistas, surgiu essa monstruosidade na área econômica do governo que não tem paralelo em nenhum país do mundo. $\mathrm{O}$ Parlamento abdicou de suas responsabilidades e prerrogativas no que tange à situação fiscal do País em duas décadas.

O Presidente da República, mesmo o 
eleito em 2018, fica impedido de estabelecer uma política econômica por dez anos no mínimo, podendo ser o prazo estendido por mais uma década. Esvazia-se a democracia, pois não adianta o eleitor fazer a escolha de um dado programa de candidato. A ditadura de Pinochet, que foi o laboratório das políticas neoliberais desde os anos 1970 e 1980, e a intervenção recente da troika sobre a Grécia não ousaram tanto. Assim, não adianta o povo votar no presidente, nos deputados e nos senadores da sua preferência, pois, a não ser que ocorra uma mudança na correlação de forças, possibilitando os votos parlamentares necessários para a aprovação de uma emenda constitucional substitutiva à EC-95 ou um questionamento admitido pelo Supremo Tribunal Federal, dificilmente poderá ocorrer uma alteração dessa política definida por um governo sem votos que assumiu o poder em 31 de agosto de 2016.

De positivo, nota-se uma crescente indignação das pessoas e da sociedade civil organizada quando tomam conhecimento do que as forças políticas e econômicas que assaltaram o poder estão fazendo contra o País e contra o seu povo. Desse modo, setores democráticos e populares cada vez mais discutem a situação, mobilizam-se, articulam-se e organizam-se para resistir ao golpe, a exemplo do Fórum da RSB, que agrega entidades e instituições comprometidas com a democracia, com a RSB e com o SUS e participa da Frente Brasil Popular e da Frente Povo sem Medo,

A difusão de denúncias e críticas desde o início do governo Temer indica a potencialidade de mobilizar consciências críticas acerca de uma concepção ampla de saúde e de fortalecer um convite para a ação, resistindo contra o golpe continuado. Estimula a construção de uma pauta democrática para a articulação política, partindo da bandeira de 'NENHUM DIREITO A MENOS' com um alargamento de demandas e lutas por outras gerações de direitos: direito a um ambiente saudável, direito à cidade, direito ao lazer, direito ao gozo estético, direito à felicidade etc.
A 'Agenda Estratégica para a Saúde no Brasil'18, composta por $\mathbf{5}$ diretrizes voltadas para uma política de saúde '5 estrelas' e subscrita por 9 importantes entidades vinculadas ao movimento sanitário, tem sido proposta para os debates nas eleições de 2018. Do mesmo modo, a 'Tese do Cebes 2018-2019'19 apresenta uma análise da conjuntura internacional, nacional e setorial, destacando a tensão entre o capitalismo e a democracia, o golpe de 2016 e destruição da cidadania, do direito à saúde, do universalismo e da integralidade, com o fortalecimento da ideia de saúde como mercadoria. Propõe um conjunto de medidas em defesa da democracia e contra o capitalismo, explicitando as bases e princípios da entidade por democracia e saúde, assim como os caminhos para a luta.

Não cabe, portanto, pensar estratégias setoriais diante da gravidade da situação atual. Não há viabilidade na reversão desse quadro, com garantia do financiamento público ao SUS, sem uma grande mobilização democrática e popular com atores sociais capazes de incluir temas na agenda do Estado. Tanto o direito à saúde quanto o SUS, para serem preservados, supõem lutas conjuntas em defesa da seguridade social e dos direitos civis, políticos, sociais e ambientais, com outras frentes de forças que defendam a democracia, os direitos humanos e as conquistas sociais e se oponham ao 'novo regime fiscal', à Reforma da Previdência e à Reforma Trabalhista. Apesar de várias palavras de ordem e propostas que surgem em busca de saídas imediatas, ainda não se vislumbra um cenário que não seja o da resistência e do acúmulo de energias políticas para alterar a correlação de forças na conjuntura.

\section{Comentários finais}

É possível sistematizar na análise dessa conjuntura pelo menos três vias de ataque ao SUS. A primeira, a via ideológica, quando a mídia, políticos, gestores, economistas, 
profissionais de saúde e segmentos da classe média defendiam um SUS pobre para pobres. A segunda, a via política, quando o Legislativo e o Executivo aprovaram a participação do capital estrangeiro na saúde, terceirizações e planos privados de saúde, além das propostas de obrigatoriedade para todos os trabalhadores e dos 'planos populares'. A terceira, a via econômica, mediante o subfinanciamento crônico, DRU, DRE, DRM, subsídios ao setor privado e a EC-95.

Essas vias de reprodução do golpe do capital na saúde representaram um desastre para os direitos civis, políticos e sociais e um ataque à democracia, à Constituição de 1988 e às conquistas sociais e ambientais. Esse golpe de empresários, urdido pela Federação das Indústrias do Estado de São Paulo (Fiesp), Confederação Nacional da Indústria (CNI), Confederação Nacional da Agricultura (CNA), Federação Brasileira de Bancos (Febraban) etc., usou a mídia e parte da classe média para realizar uma intervenção parlamentar com a chancela do Judiciário. Na saúde, o subfinanciamento constitucionalizado por intermédio da EC-95 (teto dos gastos) se apresenta como um dos mecanismos mais drásticos para o desmonte do SUS.

A tensão entre conservação e mudança, entretanto, permite considerar a possibilidade de surgimento de sujeitos da antítese ${ }^{4}$ capazes de criar fatos políticos e de estimular a tomada de consciência crítica, contribuindo para o fortalecimento de movimentos sociais comprometidos com um projeto contra-hegemônico que contemple, além dos interesses específicos dos trabalhadores, as lutas contra o sexismo, racismo, discriminação sexual e defesa do ambiente, entre outras. Esta pluralidade de vozes na democracia pode reforçar a cadeia de equivalências entre as lutas contra as distintas formas de opressão e subordinação nas relações sociais, aproveitando-se dos distintos antagonismos presentes na sociedade contemporânea ${ }^{20}$.
A materialidade e a institucionalidade construídas nas últimas três décadas sugerem que não é qualquer golpe que pode acabar com o SUS. Algum SUS pode permanecer, mesmo que seja um arremedo, um simulacro: um SUS que se confunde com 'saúde pública' destinado exclusivamente aos pobres, ao controle de epidemias e ao atendimento do que não interessa à iniciativa privada; um SUS de uma 'saúde pública' confinada às ações preventivas e assistenciais para os que não têm acesso ao mercado e apoio ao setor privado nos procedimentos de alto custo; um SUS distante das diretrizes da igualdade, da universalidade e da integralidade propostas pela RSB e concebidas pela saúde coletiva.

Resignar-se a essa tendência significa minar o caráter solidário de um sistema de saúde universal para o País. A repugnância diante dos ataques do governo sem votos das cidadãs e cidadãos, ilegítimo, e da direção impressa à política setorial pelo Ministério da Saúde exige a revitalização das instâncias de controle social, os diálogos do movimento da RSB com distintos parceiros, tais como o Conselho Nacional de Saúde (CNS), Conselho Nacional de Secretários de Saúde (Conass), Conselho Nacional de Secretarias Municipais de Saúde (Conasems), Associação Nacional do Ministério Público de Defesa da Saúde (Ampasa), Confederação Nacional dos Bispos do Brasil (CNBB), Ordem dos Advogados do Brasil (OAB), entidades representativas de profissionais de saúde e movimentos sociais comprometidos com a democracia e com a luta contra o fascismo, pela garantia dos direitos sociais, contra o racismo e contra todas as formas de discriminação. Nessa perspectiva, apresenta-se a continuidade e a intensificação da luta em diversos espaços políticos, enfrentando os desafios da radicalização da democracia para a construção de um novo Estado de Bem-Estar Social no Brasil. 


\section{Colaboradores}

Teixeira CF contribuiu significativamente na revisão crítica do conteúdo e participou da aprovação da versão final do manuscrito.
Paim JS contribuiu substancialmente para a concepção, planejamento, análise e interpretação dos dados, elaboração e revisão crítica da versão preliminar e participou da aprovação da versão final do manuscrito.

\section{Referências}

1. Conill EM. A importância da continuidade dos sistemas nacionais europeus para as políticas de saúde na América Latina. Cad Saúde Pública. 2014; 30(11):2253-2255.

2. Giovanella L, Stegmüller K. The financial crisis and health care systems in Europe: universal care under threat? Trends in health sector reforms in Germany, the United Kingdom, and Spain. Cad Saúde Pública. 2014; 30(11):2263-2281.

3. Ottersen OP, Dasgupta J, Blouin C, et al. The political origins of health inequity: prospects for change. Lancet Commissions [internet]. $2014 \mathrm{fev}$ [acesso em 2018 jul 5]; 383(9917):630-667. Disponível em: https://www.thelancet.com/journals/lancet/article/ PIIS0140-6736(13)62407-1/abstract.

4. Paim JS. A Constituição Cidadã e os 25 anos do Sistema Único de Saúde. Cad Saúde Pública. 2013; 29(10):1927-1953

5. Costa AM, Bahia L, Scheffer M. Onde foi parar o sonho do SUS? Le Monde Diplomatique Bras. 2013; 69:30-31.
6. Marques T, Mendes A. Uma decisão favorável às OSS: impasses à construção do SUS [internet]. Domingueira da Saúde 012/2015. 2015 jun 28 [acesso em 2017 ago 18]. Disponível em: http:// idisa.org.br/img/File/Domingueira\%20da\%20 Sa\%C3\%BAde\%20-\%20012\%202015\%20-\%20 $28 \% 2006 \% 202015$.pdf.

7. Singer AE. A (falta de) base política para o ensaio desenvolvimentista. In: Singer A, Loureiro I, organizadores. As contradições do lulismo: a que ponto chegamos? São Paulo: Boitempo; 2016. p. 21-54.

8. Braga R. O fim do lulismo. In: Jinkings I, Doria K, Cleto M. Por que gritamos golpe?: para entender o impeachment e a crise política no Brasil. São Paulo: Boitempo; 2016. p. 55-60.

9. Oliveira C. O ódio como discurso político propagado nas redes e nas ruas a serviço do golpe. In: Rovai R, organizador. Golpe 16. São Paulo: Publisher Brasil; 2016. p. 41-54.

10. Scaff FF. A DRU, os direitos sociais e o pagamento dos juros da dívida [internet]. Consultor Jurídico. 
2015 jul 14 [acesso em 2015 jul 22]. Disponível em: https://www.conjur.com.br/2015-jul-14/contas-vista-dru-direitos-sociais-pagamento-juros-divida.

11. Sestelo JAF. Planos e seguros de saúde do Brasil de 2000 a 2015 e a dominância financeira [tese]. Rio de Janeiro: Universidade Federal do Rio de Janeiro; Centro de Ciências da Saúde; Instituto de Estudos de Saúde Coletiva; 2017. 648 p.

12. Monteiro MG. Trayectoria y cambios de dirección en las políticas públicas: análisis de la reforma del sistema sanitario brasileño (1975-2015) [tese]. Barcelona: Universitad Autónoma de Barcelona; Departamento de Ciencia Política y Derecho Público; 2016. 327 p.

13. Miguel LF. A democracia na encruzilhada. In: Jinkings I, Doria K, Cleto M. Por que gritamos golpe?: para entender o impeachment e a crise política no Brasil. São Paulo: Boitempo; 2016. p. 31-37.

14. Fagnani E. Política Social no Brasil (1964-2002): Entre a Cidadania e a Caridade [tese]. Campinas: Universidade Estadual de Campinas; Instituto de Economia; 2005. 587 p.

15. Titelman D, Centrángolo O, Acosta OL. Universal Health Coverage in Latin American Countries: how to improve solidarity-based schemes. Lancet. 2015 abr; 385(9975):1359-1363.

16. Coelho E. Uma esquerda para o capital. Crise do Marxismo e Mudanças nos Projetos Políticos dos
Grupos Dirigentes do PT (1979-1998) [tese]. Niterói: Universidade Federal Fluminense; Programa de Pós-Graduação em História; 2005.

17. Brasil Debate, Fórum 21, Fundação Perseu Abramo, et al. Por um Brasil justo e democrático: o Brasil que queremos: subsídios para um projeto de desenvolvimento nacional. [sem local]: Brasil Debate; 2015 [acesso em 2017 jul 22]. v. 2. Disponível em: http:// plataformapoliticasocial.com.br/por-um-brasil-justo-e-democratico-2.

18. Associação Brasileira de Saúde Mental, Associação Brasileira de Saúde Coletiva, Centro Brasileiro de Estudos em Saúde, et al. SUS igual para todos: Agenda Estratégica para a Saúde no Brasil: 5 diretrizes de uma política de saúde 5 estrelas para pobres e ricos. Rio de Janeiro: Abrasco; Cebes; 2011.

19. Centro Brasileiro de Estudos de Saúde. Cebes na luta: transformar e radicalizar a Democracia para assegurar Direitos Sociais e Saúde: Teses do CEBES 2018-2019. Rio de Janeiro: Cebes; 2018.

20. Laclau EE, Mouffe C. Hegemonia y estrategia socialista: hacia una radicalización de la democracia. 3. ed. Buenos Aires: Fondo de Cultura Económica; 2010.

Recebido em 11/07/2018

Aprovado em 04/09/2018

Conflito de interesses: inexistente

Suporte financeiro: não houve 